\title{
FEATURES OF ENVIRONMENTAL EDUCATION IN CHEMISTRY CLASSES
}

\author{
Shoira Kasimovna Tashbaeva \\ Senior Lecturer, Department Of Chemistry Gulistan State University (Uzbekistan) \\ Feruza Abdullayevna Lapasova \\ Teacher, Department Of Chemistry Gulistan State University (Uzbekistan)
}

\section{ABSTRACT}

The article presents the experience of greening the subject of chemistry and the program of the course of choice for students of an educational institution aimed at developing an ecological culture and a responsible attitude to nature, at developing skills in working with reagents and conducting research.

KEYWORDS:- Ecology, age, competence, strategy, education, modernization, nature, culture, system, intellectual

\section{INTRODUCTION}

The history of mankind is inextricably linked with the history of nature. At the present stage, the issues of traditional interaction in the "Man Nature- Society" system have grown into a global environmental problem. As W. R. rightly pointed out. We have no right to remain ignorant of the environmental laws governing man, nature, and history. Otherwise, we will perish under the wreckage of our own civilization." To do this, it is necessary to constantly engage in the education of ecological culture and increase the level of environmental knowledge, starting from primary school age, since the knowledge acquired at this time can later be transformed into strong beliefs.

The strategy for modernizing general education emphasizes that "the main result of an educational institution's activity is not a system of knowledge, skills and abilities in itself, but their transformation into a set of key competencies of students in intellectual, legal, informational and other areas." This will allow graduates to successfully cope with any problems, while not forgetting about the ecological context of human life, about the environmental laws governing man, nature, and society. bxModern teachers need to understand the features of environmental education in the context of globalization of environmental problems. Modern concept of General environmental education drawn up in accordance with the Concept of state educational standards for General education of the second generation (GOS Uzbekistan); based on the system-activity and cultural-historical approaches, the main provisions of the program 
CURRENT RESEARCH JOURNAL OF PEDAGOGICS 2(9): 180-182,

September 2021 DOI: https://doi.org/10.37547/pedagogics-crjp-02-09-37

ISSN 2767-3278

(C)2021 Master Journals

\section{Crossref do) 8 Google}

Accepted 25 $5^{\text {th }}$ September, 2021 \& Published 30 ${ }^{\text {th }}$ September, 2021

of development and formation of universal educational actions of the program of spiritual and moral education, socialization, and education, the formation of the values of health and healthy lifestyle the state of Uzbekistan.

According to the State Educational Standard of Uzbekistan, environmental education is implemented as an environmental component of basic academic subjects, as well as in the form of a variable part-time component and in extracurricular activities. Natural science subjects provide for the education of students with a responsible and careful attitude to the environment; mastering the ecosystem cognitive model and its application in order to predict environmental risks to human health, life safety, and environmental quality; awareness of the importance of the concept of sustainable development. Today, a comprehensive school is designed to lay the foundation for the formation of a person with a new way of thinking and behavior in the environment - ecological. As you know, chemistry is a subject where environmental aspects can be reflected in almost every lesson, as well as in extracurricular activities. When studying any topic, it is possible and necessary to raise environmental issues [1, $2,3]$. In the process of teaching chemistry in grades VIII-XI, it is important to consider the problems of protecting the environment from chemical pollution. В основу Ecologization is based on ideas about the relationship between the composition, structure, properties and biological function of substances, their dual role in wildlife; biological interchangeability of chemical elements and the consequences of this process for organisms, the causes of disruption of biogeochemical cycles. At the final stage of school education in grades $\mathrm{X}-\mathrm{XI}$, prerequisites are created for understanding such ecological patterns as cyclicity and continuity of processes, and the exchange of substances between the constituent components of the biosphere.: a) maintain the right of every person to live in such a natural and social environment, which would support his dignity, health

and spiritual well-being; b) causing serious concern for the environment (global warming, depletion of the stratospheric ozone layer, acid rain, the accumulation in soil of toxic heavy metals and pesticides, contamination of large areas with radionuclides, the depletion of natural resources of the planet). When drawing up thematic planning, we take into account environmental aspects. For example, when studying the topic "Electrolytic dissociation of substances", we pay special attention to the use of electrolytes in industry, agriculture, medicine, and everyday life, and focus on the mechanism of acidification soil, water. When studying redoxreactions, we pay attention to the fact that they serve as sources of toxic substances in the natural environment [2]. When studying the topic " Oxygen. Oxides. Burning" we pay special attention to ozone (the strongest oxidizer and toxicant), sulfur as an element that is part of substances that are pollutants of the natural environment, sulfur oxides as pollutants of the natural environment, the consequences of the formation of sulfuric acid rain (impact on water bodies, coniferous trees).

When studying the topic "Nitrogen subgroup", we consider ammonia as an environmental pollutant. Positive and negative effects of ammonia and its compounds on living organisms. Ammonia production as an example of an environmentally friendly technology. Problems of nitrogen oxides accumulation in the atmosphere, their participation in photochemical smog, acid rain formation. Chemical methods for cleaning gaseous emissions containing nitrogen oxides. Studying the subgroup of "Carbon" we get acquainted with the concept of adsorption as one of the methods of trapping toxic substances. Carbon oxides are atmospheric pollutants. The effect of carbon dioxide on the vital activity of 
CURRENT RESEARCH JOURNAL OF PEDAGOGICS 2(9): 180-182,

September 2021 DOI: https://doi.org/10.37547/pedagogics-crjp-02-09-37

ISSN 2767-3278

(C)2021 Master Journals

Crossref do) 81 Google

Accepted 25th September, 2021 \& Published 30 ${ }^{\text {th }}$ September, 2021

organisms; reduced photosynthesis in plants and impaired respiration in animals, humans. Toxic effect of carbon monoxide. The greenhouse effect: causes, possible consequences, and ways to prevent them. Silicon compounds as environmental pollutants of living organisms. When studying the topic "General properties of metals", we talk about the dual role of metal ions in nature, depending on their concentration. We consider corrosion as a factor of environmental pollution. Calcium and magnesium are macronutrients that are part of animal and plant organisms. Pollution of the environment leads to the replacement of calcium with strontium in human and animal organisms. The effect of aluminum on the human nervous system. Negative effect of aluminum on the respiratory system of fish. By studying"Polymers" we say that the production of polyethylene, polypropylene, and polyvinyl chloride brings considerable environmental problems for the natural environment. This use of various toxic monomers and catalysts, the formation of wastewater and gas emissions, the neutralization of which is associated with high energy, raw materials and labor costs, is not always performed by manufacturers. Currently, two main approaches are being actively developed to clean up the natural environment from plastic waste: disposal (storage of waste in landfills) and recycling. Dumping plastic waste is a time bomb and puts today's problems on the shoulders of future generations. A radical solution to the problem of "polymer waste", according to experts, is the creation and development of a wide range of polymers that can biodegrade under appropriate conditions.биодеградировать on components that are harmless to living and inanimate nature. In conclusion, it should be noted that there is a need for further deeper development of the problem of environmental education of schoolchildren. This work allows us to solve a number of tasks: a) development of environmental ethics of students, responsibility in their relations with nature; b) aesthetic, moral education, education of love for the Motherland; c) formation of a sense of belonging to one's time, personal responsibility for everything that happens around. So, environmental education in chemistry lessons is necessary for the harmonious development of schoolchildren and is a necessary form of work.

\section{REFERENCES}

1. Andrus J. Smith Introduction to Environmental Chemistry, Moscow: Mir Publ., 1999.

2. Efimova E. V., Chupanova L. V., Naumova L. G., Mirkin B. M. On the ecological component of chemical education. - 2003. - № 9.

3. Zhigarev, I. A., Ponamareva N. M., Chernova N. M. Fundamentals of ecology. Collection of tasks, exercises, and practical papers.- M.: Bustard, 2002. - 206 p.

4. Kvasnichkova, D., Kalinina V. Schemes for ecology and methodological development to them.- M.: Sustainable World, 2001. - 78 p. 